\title{
The Application of 'Elite Interviewing' Methodology in Transdisciplinary Research: a Record of Process and Lessons Learned during a 3-Year Pilot in Urban Planetary Health Research
}

\author{
Gabriel Scally • Daniel Black (D) Paul Pilkington • \\ Ben Williams • Janet Ige-Elegbede • Emily Prestwood
}

Accepted: 9 February 2021 / Published online: 14 May 2021

(C) The Author(s) 2021

\begin{abstract}
This paper sets out the rationale and process for the interviewing methodology utilized during a 3-year research pilot, 'Moving Health Upstream in Urban Development' (UPSTREAM). The project had two primary aims: firstly, to attempt to value economically the health cost benefits associated with the quality of urban environments and secondly, to engage with those in control of urban development in the UK in order to determine what are the barriers to and opportunities for creating healthy urban environments, including those identified through the utilisation of economic valuation. Engagement at senior level with those who have most control over key facets of planning and development implementation - such as land disposal, investment, development delivery and planning
\end{abstract}

UPSTREAM was a 3-year pilot funded by the Wellcome Trust under their Our Planet Our Health (OPOH) Programme, which supports researchers to take on the challenges that (i) food systems, (ii) increasing urbanisation and (iii) climate change pose to our health. It was funded under the second round of pilot awards and sits within the urbanisation theme.

\section{G. Scally}

University of Bristol, Bristol, UK

\section{Black}

Daniel Black + Associates $\mid \mathrm{db}+\mathrm{a}$, Bristol, UK

e-mail: Daniel.Black@bristol.ac.uk

P. Pilkington $\cdot$ B. Williams $\cdot$ J. Ige-Elegbede $(\bowtie)$

University of the West of England, Bristol, UK

e-mail: Janet.Ige@uwe.ac.uk

E. Prestwood

University of Birmingham, Birmingham, UK permission-was central to the approach, which encompassed the adoption of 'elite interviewing', a method developed in the USA in the 1950s and used in the political sciences but relatively unutilized in the health and environmental sciences [1]. Two rounds of semi-structured interviews were undertaken with 15 senior decisionmakers from the UK's main urban development delivery agencies, both public and private. The 'elite interviewing' approach successfully enabled the UPSTREAM project to capture and analyse the information received from the interviewees, all of whom held influential or leadership posts in organisations that are important actors in the process of planning, developing and constructing the built environment in the UK. Having academic and practitioner research leads on an equal footing created some minor tensions, but it also appeared to strengthen the rigor of the approach through a broad knowledge of context 'inhouse'. This form of co-production at times challenged academic traditions in qualitative analysis, but it also appeared to build trust with interviewees and provided greater clarity of the real-world context under investigation. Findings from this study are written up in a separate paper.

Keywords Elite interviewing · Methodology · Urban development $\cdot$ Planetary health $\cdot$ Upstream

\section{Introduction}

The pilot 'Moving Health Upstream in Urban Development' (UPSTREAM) was funded by the Wellcome Trust under their Our Planet Our Health (OPOH) 
programme, which supports researchers to take on the challenges that (a) food systems, (b) increasing urbanisation and (c) climate change pose to our health. $\mathrm{OPOH}$ aims to provide strong evidence for action so that policymakers, businesses and the public can make more informed decisions on things that affect the environment and health [2]. It was led by a steering group of academic and external practitioner-researchers and had two primary aims:

1. To develop the use of economic valuation in understanding the quality of the urban environment and its measurable impact on human and planetary health [3]

2. To understand from those in control of the urban development in the UK what the main barriers and opportunities are in creating healthy urban environments

This paper sets out the rationale for the pilot, providing a brief overview of the evidence linking urban environments with human and planetary health outcomes, alongside a description of the challenges in enabling substantive change in this area (within the UK specifically, but with lessons of relevance to geopolitical and urban development contexts with shared systems; broadly, European and other 'Western' OECD countries). We describe the underpinning considerations vital for effective interviewing in this context, the sample of interviewees, why and how they were selected and the interviewing and analysis processes undertaken. The strengths and limitations of the approach are explored, along with description of how we sought to overcome impediments and how we propose to develop further this approach.

The interview findings, key discussion points and priority research areas are presented in a separate paper [4].

\section{Background and Project Rationale}

Urban environments and public health have a long, shared history. Although the specifics of population health risk have changed significantly since the nineteenth century sanitary revolution, the rise of noncommunicable diseases (e.g. cancers, diabetes, respiratory illnesses) and global environmental risk factors (e.g. flooding, heat waves, resource depletion, migration) are due in no small part to poor urban environments and linked behaviors, and they are placing increasing stress on our human and planetary life support systems in the UK as elsewhere across the urbanising world [5-10].

Significant research has been undertaken on healthy and sustainable urban planning and design over recent decades and is represented widely within the 'grey literature' $[8,11-20]$.

We see planning and design of the built environment as being in the 'midstream' of the urban development process, as opposed to those root cause decisions made further upstream at the city level and above, which include key points of influence such as 'disposal' (sale) of land, investment controls and control of delivery process $[21,22]$. Figure 1 illustrates the range of different actors, disciplines and decision areas along the urban development stream of activities.

Despite the UK now having globally renowned expertise and workforces in the built environment professions, our towns and cities continue to be polluted and dominated by cars, and buildings and public spaces are often of poor quality are lifeless [8, 23-26]. Behavior in urban environments is overwhelmingly directed towards consumption and unhealthy eating and drinking. This, plus limited opportunities for accessing nature which means we are increasingly disconnected from the natural world, is impacting significantly on our physical and mental health $[8,13,27]$.

There are increasing calls from the public health practice and linked academic communities to examine factors upstream, not just at the stage of design of the built environment itself [28] but to consider the 'commercial determinants of health' and issues such as global flows of human resources and capital [29-31].

We have already described the further challenge areas, which we suggest include valuation failure and specifically market and government inability to internalize current and future costs to human and planetary health; the disconnection between research and practice resulting in misunderstanding, an underutilized knowledge base and limited impact; and the sheer complexity of actors and processes involved along with other factors in influencing urban development decision-making [32]. We proposed specifically the need for engagement and co-production with those in control of the development delivery processes, alongside the need for innovative new process for balancing engagement with community representatives affected by these upstream decisions. 


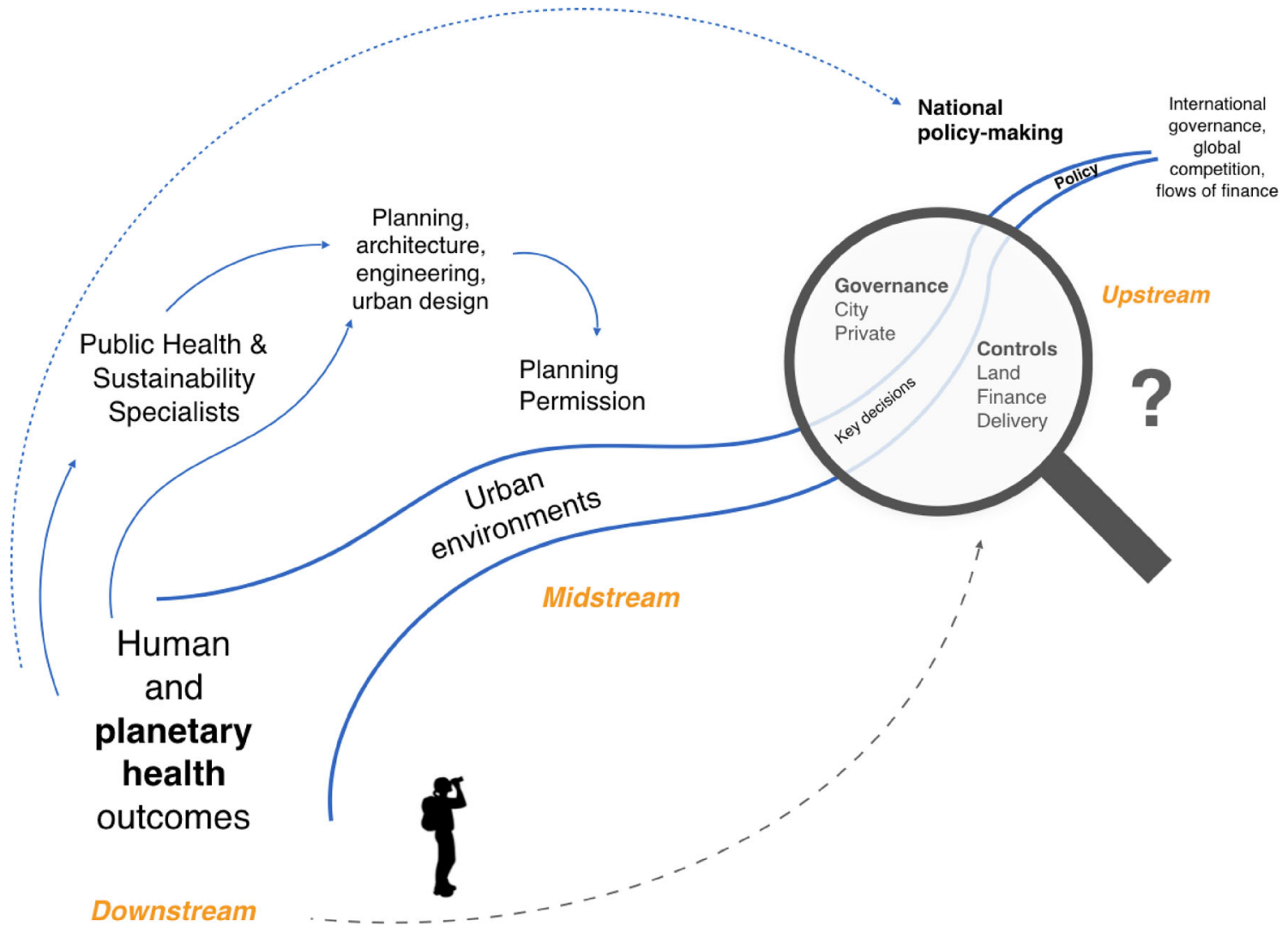

Fig. 1 An illustration showing (a) the different activities in urban development and which decisions and actors take precedence, (b) the relative familiarity of the health and urban research community with downstream and mid-stream activity and (c) the relative disconnect between those aware of public and planetary health outcomes downstream and those responsible for critical decisionmaking far upstream.
Building on this project rationale, central to our approach were the following key aspects: first, the use of emerging non-market economic valuation methods to

Box 1 Key points relating to elite interviewing

- The entire approach should be conducted in a highly professional manner

- Interviews should invariably be conducted by the most senior investigators

- A limited number of key probes for areas in which information is sought should be at the core of the interview

- Effective note-keeping prior to, during the course of, and after the interview is vital, as non-textual learning may be very important

- Rapid analysis and coding of the output of the interview is important so as to inform and develop the process and the areas of enquiry as the study proceeds

- Time should be set aside to prepare and rehearse for the interviews

- Preparation should include a background brief on each interviewee and their organisation support decision-making more informed about 'external' costs; second, the central role of experienced practitioner-researchers as a core part of the research team leadership, responsible for bridging the gaps between the worlds of academia and practice in this specific area; third, an unbounded approach to investigation based on consideration of whole systems (and other linked systems); and finally, a focus within the pilot on senior decision-makers and on methodological approaches that enable effective data collection and analysis given the inherent constraints and factors influencing engagement with those with limited time [21].

Implicit within this starting position too are the notions of inter- and trans-disciplinary working, or at the very least the need for co-production with a wide range of stakeholders. This is an area very familiar to those who work in urban planning and related fields (e.g. 'masterplanning', urban design review, health and sustainability assessment) where public participation and 
community consultation, engagement and involvement have long been practiced and are widely required (despite it now being widely recognized as paying 'lip service' to the notion of genuine community involvement) [33-38]. There is now considerable literature on the benefits of co-production in research and across many fields - e.g. healthcare ("patient and public involvement or engagement'), law or product designand using a wide variety of processes and with a range of communities, most notably perhaps the lay public, though also with targeted sector-specific or topic-related groups (e.g. civil service, local government, consumers, commercial partners) [39-44]. There is also a 'dark side' to co-production in that it can often be perceived as a universal good to aspire to greater levels of inclusivity, which in and of itself presents its own challenges (e.g. raising of expectations, poor understanding of who to involve, 'consultation fatigue', disconnect between involvement plan and resource available, not keeping your 'eye on the prize' of reduction in NCD) [45-47]. Finally, how we approach co-production has implications beyond research design to broader issues of research governance and the structural challenges across the research ecosystem. Key points for consideration appear to include, e.g. overspecialisation within academia and the prevailing disconnection between academia and the real world and a growing demand for 'knowledge brokers' and 'blended professionals', alongside a similar challenge to co-production: the 'dark side of knowledge brokerage'. [21, 48-53]

\section{Objectives and Phases}

The main objectives were as follows:

1. To demonstrate to decision-makers the hidden costs of poor-quality urban development

2. To test what impact monetary valuation of health outcomes may have on decision-makers

3. To identify the barriers facing (and opportunities open to) decision-makers

4. To validate this taxonomy of barriers and opportunities and have endorsed the resulting strategy

5. To disseminate the results nationally and internationally

In order to achieve these objectives, the project was split into three balanced and overlapping phases:
1. An umbrella review (a systematic review of reviewlevel evidence) including over 200 studies from the health literature examining associations between the urban environment and health outcomes splits into five main search areas: buildings, transport, natural environment, neighborhood design and food (Fig. 2). Evidence in each area was obtained from a systematic search of relevant electronic databases and other online sources, using specified keywords, with quality assessment of identified studies and narrative synthesis of findings. The areas of search were derived through a comparative exercise mapping categories from five different assessment tools: (i) the Health Map, a graphical prompt listing the primary determinants of health linked to the built environment, was used as a stem checklist; (ii) the Vancouver Health Impact Assessment Toolkit; [54, 55] (iii) BREEAM Communities; [56] (iv) HUDU Rapid HIA [57]; and (v) the Egan Review. [58] Climate change was seen as a 'multiplier' that was factored across all other categories.

2. A valuation of the urban-health data and associated economic cost-benefits. [3]

3. Two rounds of semi-structured interviews with 15 senior public and private sector decision-makers from the urban development world. [4]

\section{Elite Interview Method and Sampling}

The study used a qualitative 'elite interviewing' approach consisting of two rounds of in-depth semi-structured interviews (both face-to-face and over the telephone) with 15 interviewees. For this research, the use of the term 'elite' was consistent with its commonly used definition as a member of a group of persons exercising a major share of authority or influence within a larger group or organisation. Elite interviewing has almost exclusively been applied at top levels within coherent occupational or professional groupings, e.g. US politicians and healthcare executives, yet its flexibility and underpinning theory fit well with the multisectoral group of interests represented amongst our target interviewees. [59-61] Our proposition was that with the right transdisciplinary team and approach, it can overcome, in a demanding multi-sectoral arena, both methodological issues such as power relations as well 
as practical issues experienced by junior researchers such as gaining access, establishing trust and dealing with interpersonal challenges. [62, 63]

While it can be categorized as a type of semistructured interviewing methodology, elite interviewing demands a nuanced approach to preparation, implementation and data analysis, which is crucial for effective research (Box 1).

The elite interview requests were targeted at individual senior executives from the public and private sector, who were likely to have a full understanding not only of their own organisations but how their organisations fit within the wider system (Table 1). Candidates for interview were identified mainly through existing practitioner networks identified in purposeful discussion amongst the multidisciplinary research team members. As UPSTREAM had been actively communicating its research activity, one interviewee came via their expression of interest on LinkedIn. All interviewees expressed a preexisting interest in the research area (there had already been considerable work industry-wide on sustainability issues, and urban health was a growing area of interest). They did not receive a stipend.

In choosing to interview those in the 'elite' category, a differentiation is drawn between those who have 'interpretive power' based on their knowledge and skill (the experts) and those who have 'formative power' because of their position in organisations and their direct involvement in, or proximity to, decisionmaking (the elite). [64] They were either at director or chief executive level in their organisation or in a position where they regularly controlled or influenced decision-making on urban development at the highest level. Some of the executives were supported in the interviews by the health/sustainability leads from their organisation. Of those interviewed, eleven were male and four female, the latter all in the public sector.

Defining those to be interviewed was a key task, and, as Littig has pointed out, sampling in elite interviewing 'does not adhere to quantitative conceptions of representativity'. [64] The group was a purposive sample, hitherto unknown to the lead interviewer, and derived mainly through existing networks, although one interviewee expressed their interest in taking part following a notice posted on LinkedIn. The justification for this was the relative inaccessibility of senior decision-makers in this field, which takes in to account the 'distance' between researchers and practitioners on the one hand and the public health sector and our target sample group (developers, investors and landowners) on the other.

It is worth underlining that the focus was on the planning and management of urban areas, including large-scale mixed-use urban development projects, i.e. buildings primarily - residential, employment, retail, leisure - and supporting infrastructure (streets, public transport, green/blue infrastructure, community amenities), as opposed to specific large-scale infrastructure such as new rail, road, energy or telecommunications projects.

The first round of interviews took place between June 2017 and November 2017, and the second round took place between June 2018 and September 2018. The first round of interviews was undertaken using a framework of 13 thematic areas and associated probes (Fig. $3)$. The research team developed the first-round thematic areas and probes following informal interviews with four senior independent advisors with long experience in key areas of urban development practice: real estate, city government, estate agency and volume house building. Five second-round thematic areas and probes were identified by the research team through internal research group analysis and reflection post hoc of the field notes and coded transcripts. These were intended to allow key areas identified in the first and subsequent analysis to be explored in greater detail. Approximately a third of the time in the second-round interviews were allocated to discussion of the economic valuation findings and twothirds to deeper exploration of key themes identified.

In the analysis, we combined two main approaches: (1) synthesis by the lead interviewer who was present at every interview drawing from the interviews, field notes and corroborating against the transcriptions and (2) coding (using NVIVO) of transcriptions by three researchers who had been individually present at one or more interviews, using Braun and Clarke's framework for thematic analysis. [65] A third point of validation was sought from the wider internal project team when presenting back the summary of the synthesized analysis (Fig. 4). Informants were not part of this final reporting stage but did receive transcriptions for comment and correction during the process of theme development and analysis. The study received ethical approval from the University of the West of England. At all stages of data collection and analysis, data was stored securely in accordance with the University of the West of England's data management procedures. Quotes were anonymized in outputs, so as to preserve anonymity for participants. 


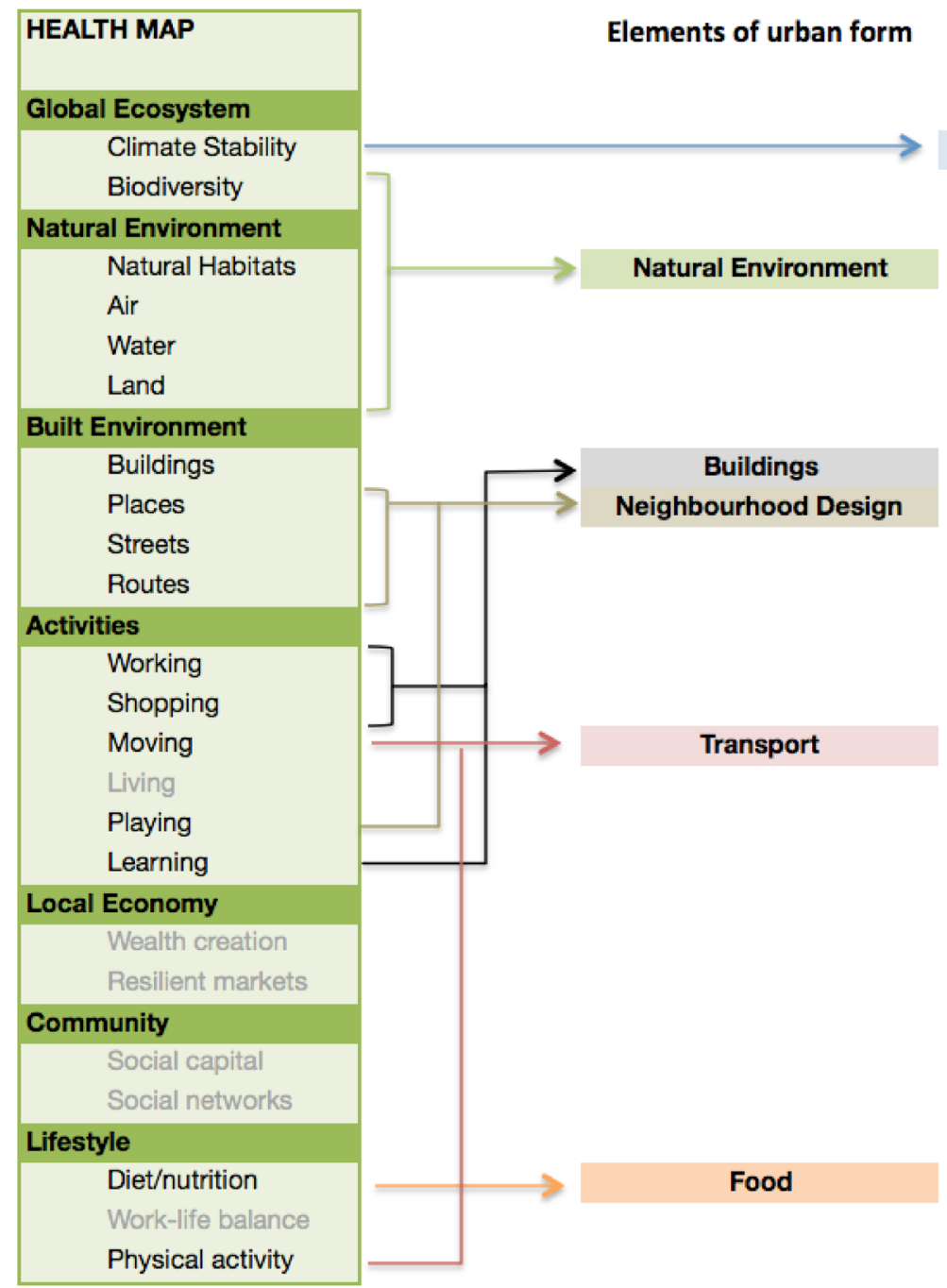

Fig. 2 The five areas of search used in the umbrella review were derived from the Health Map, a graphical prompt that lists primary determinants of health linked to the built environment. It was used

Table 1 Overview of interviewee sample showing sectors, organisations, interviewee numbers and positions within organisations

\begin{tabular}{llll}
\hline Sector & Organisation & $\begin{array}{l}\text { No. of } \\
\text { interviewees }\end{array}$ & $\begin{array}{l}\text { Position within } \\
\text { company }\end{array}$ \\
\hline Private & $\begin{array}{c}\text { - Volume } \\
\text { House-Builder } \\
\text { - Developer/Asset } \\
\text { Manager }\end{array}$ & 6 & $\begin{array}{l}\text { Senior executives } \\
\text { Sustainability/health } \\
\text { specialists }\end{array}$ \\
& $\begin{array}{l}\text { - Regeneration JV } \\
\text { - Investor Social } \\
\text { Enterprise }\end{array}$ & & \\
Public & $\begin{array}{c}\text { City Council } \\
\text { - District Council } \\
\text { - Development } \\
\text { Corporation }\end{array}$ & 5 & $\begin{array}{l}\text { Senior executives } \\
\text { Sustainability/health } \\
\text { specialists }\end{array}$ \\
\hline
\end{tabular}

as a stem checklist of categories and was compared against four other health and built environment tools. Climate is revealed as a 'multiplier' factor across all five

\section{Discussion}

The decision to adopt the elite interviewing approach resulted from an early realisation that we would need an approach to semi-structured interviewing that could take in to account the contextual factors set out above (e.g. wide range of subject matter, the need for broad practitioner expertise to facilitate discussion, time limitations). It was not only judged to be well suited to our purpose but would also be critical in ensuring we could satisfy the aims and objectives of the pilot.

Our experience during the study and the richness of the data collected appears to have born these judgements. To give one example where the approach 
1st Expert

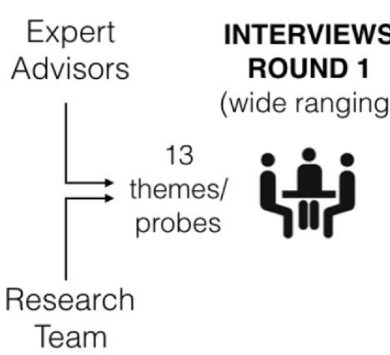

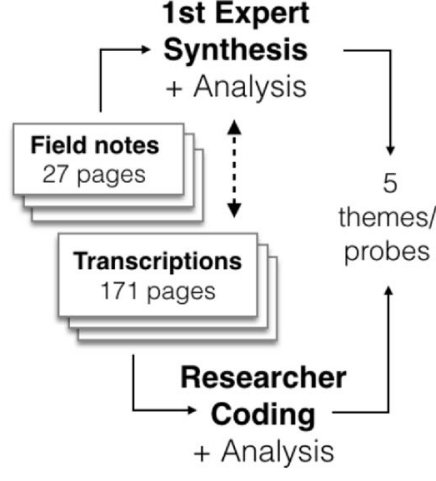

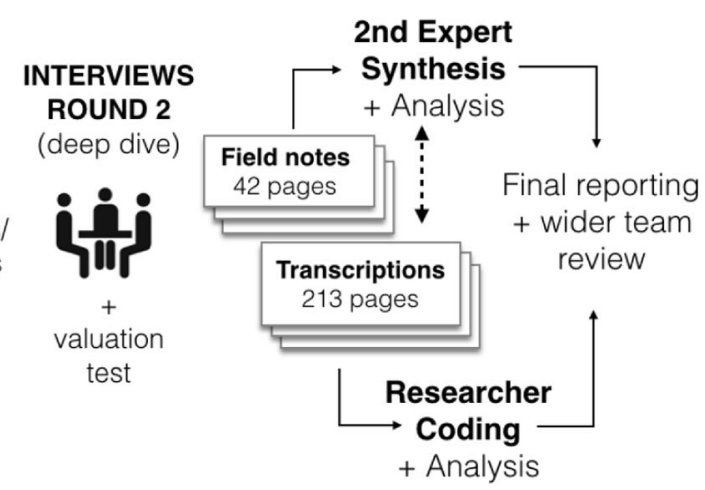

Fig. 3 Flow chart illustrating process of iterative interview theme co-development and analysis. The first round of interviews started with thirteen themes and associated probes. Five themes were selected for a 'deeper dive' in round two. In the final analysis, these themes were combined into eight main themes in the industry report and interview findings paper appeared to bear fruit, all interviewees seemed, and their behavior supported this view, to be stimulated and engaged by the conversations, which led to longer time in conversation, considerably more data and greater levels of ongoing engagement. Each interview was scheduled to run for an hour, and though one was shortened due to limited time availability of the interviewee, most ran substantially over the time agreed despite interviewees saying initially they needed to keep to time. We believe this would have been far less likely if the interview had been more tightly structured, less conversational and more question focussed (i.e. less intellectually stimulating and, potentially, perceived as less relevant).

Another example of the benefit of this nuanced approach was the nature of the interpretation and analysis. There was a difference of opinion between the academic researchers and the practitioner-researchers as to the best approach. The academic researchers understandably sought to employ a realist approach whereby the coding has primacy, [66] and should direct the analysis, given that it is drawing directly from the raw data using a widely accepted method and is corroborated by three different researchers. In contrast, a single individual referring to field notes to draw out findings, even if they were then corroborated against the verbatim transcriptions, is understandably accorded far less weight. From the practitioner-researcher perspective, however, as encompassed in the elite interviewing methodology, there is a 'significant value in the non-textual learning', and there is a need for substantial experience in order to effectively undertake the research. As Black (2006) argues, 'how can words fully express the meaning inherent in our observations, personal interviews and pictures when so much of it is subtle, hidden and contextually bound?' [67]

In order to support both positions-i.e. ensuring appropriate checks are in place while also acknowledging the primacy in this occasion of practitioner insightthe research team decided to further triangulate the approach by adopting a 'three-pronged' analysis led by the practitioner-researcher but checked firstly against the three academic researcher coding and, secondly, then checked that synthesized analysis with the wider team. Figure 4 sets out the various strengths and limitations of each approach and how, together, they were made to be mutually supportive.

We believe that the co-production between the academics in the project and the practitioner is a key learning output from the research. While it challenges traditional academic approaches to qualitative analysis, we feel that in the context of elite interviewing, it strengthens analysis by combining academic rigor with practitioner expertise, leading to outputs that reflect more fully the real-world context of the area under study.

There has been considerable critique of the elite interviewing approach. $[61,68,69]$ In addition to the recognized limitations inherent in qualitative interviewing approaches (e.g. small sample size and lack of 'triangulation'; expertise, subjective bias and influence of researchers; reporting framework and limitations), interviewing 'elites' presents a number of additional potential constraints (e.g. time availability of interviewees, knowledge of lead interviewer and associated bias, [66, 70-73] knowledge of research coders and interview bias, getting balance right between). [59, $61,74]$ These critiques have proven valuable to us in 


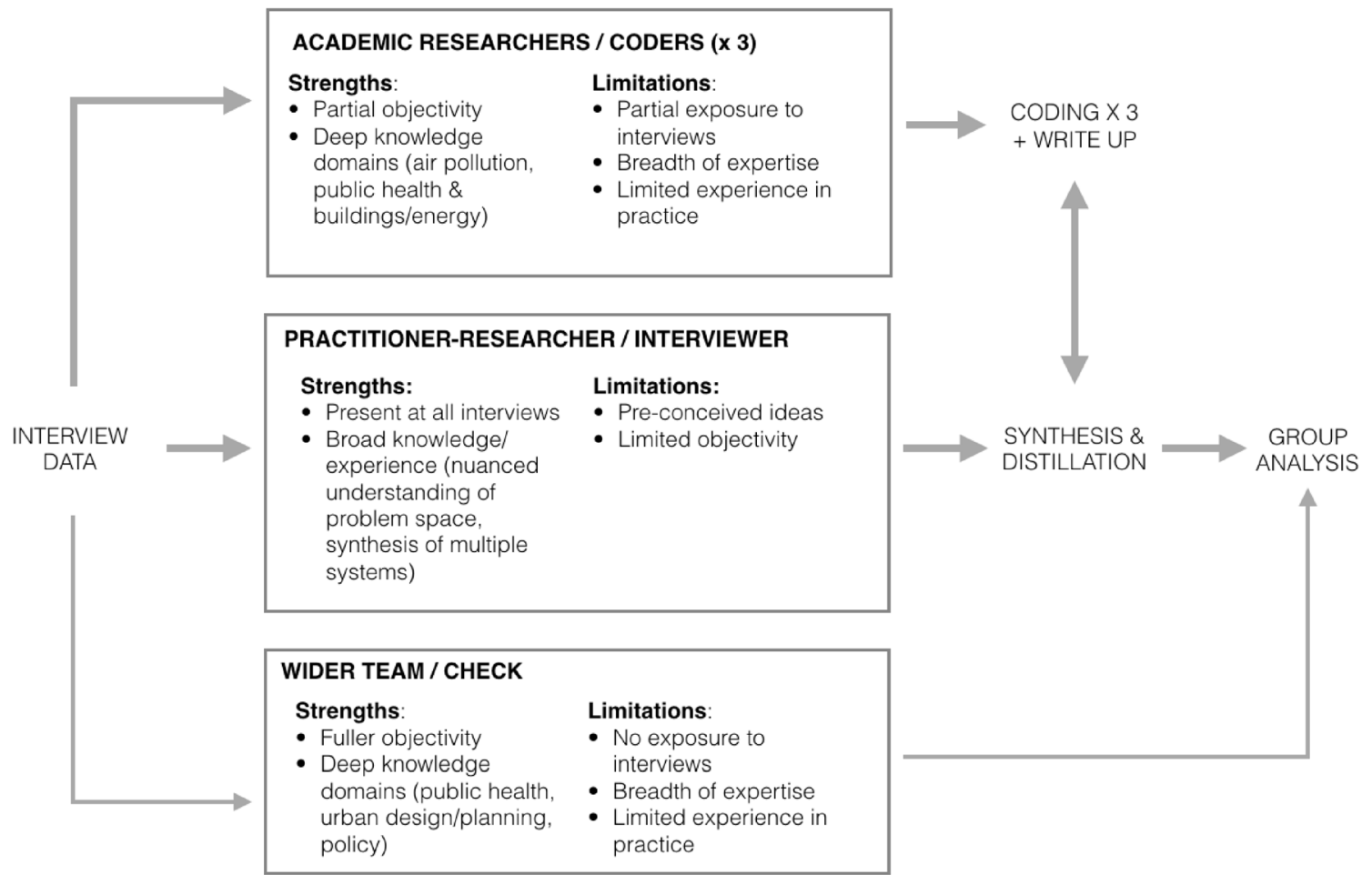

Fig. 4 Flow of 'three-pronged' analysis process aimed at shoring up shortcomings in each individual approach, setting out strengths and limitations of each

helping avoid some of the potential issues, and our operational methods have sought to avoid or mitigate many of these issues arising.

An issue to address when conducting elite interviewing is the factor that might influence the willingness of elite individuals to participate. We did not use any form of financial incentive to encourage engagement in our research. Instead, we found that participants were motivated to engage through a pre-existing interest in the sustainability and health agendas. We also feel that an important factor in our success in recruiting 'elite' participants was to have a lead interviewer who was an experienced practitioner in the field, who had a broad understanding of the sectors involved, had established expertise in at least one cognate discipline and could 'speak their language'.

In common with other qualitative approaches, the question of external validity needs to be considered. Although it is not possible to prove the external validity of our findings, we believe that the participants did represent a spread of actors across the field under study. And while it is possible that knowledge, experience and attitudes towards health and development amongst those who agreed to participate in our research may differ from others in the field (particularly given our comment in the previous paragraph), we did not observe any patterns that might point towards possible participant bias (such as high levels of refusals to participate in the research amongst those we approached).

During the carrying out of the research, we have also had researchers, both within and outside our wider team, questioning the use of the word 'elite' (both as an accurate descriptor in itself and due to it being seen as 'elitist', focusing attention on the privileged few), as well as dismissing it as either too constrained or little different from standard interviewing methods. It is clear that the term 'elite' is uncomfortable for many people and carries with it strong connotations of class, gender and racial inequality. However, the methodology of 'elite interviewing' as a means of exploring key research questions with people who have power has proven valuable in research, notably in political science, and we have found it to be appropriate and effective in the multidisciplinary context. As for the specific title 'elite interviewing', we would concur with the sentiment as expressed by Davis Riesman in 1956: 
I am not happy with the term "elite," with its connotations of superiority. Yet I have found no other term that is shorthand for the point I want to make, namely that people in important or exposed positions may require VIP interviewing treatment on the topics which relate to their importance and exposure. [75]

\section{Conclusion}

We have successfully developed and employed the 'elite interviewing' methodology, which originated in the world of political science in the USA, to a multidisciplinary group of decision-makers with considerable influence over the nature of urban development in the UK and thus it's capacity to contribute to the solution of problems associated with the causation of major noncommunicable diseases burdens in society. We maintain that this approach has been crucial to the successful carrying out of our research, giving us all-important flexibility in suiting the research implementation and analysis to task. While we acknowledge its limitations, which need to be made clear when presenting method and findings, we suggest the benefits can, if the technique is applied appropriately, far outweigh the shortfalls. We will be employing and developing the methodology further in our new 5-year research programme funded under the UK Prevention Research Partnership: 'Tackling Root Causes Upstream of Unhealthy Urban Development'. [76]

Acknowledgements The economic valuation work in UPSTREAM was undertaken by Eleanor Eaton and Alistair Hunt at the University of Bath's Department of Economics. All members of UPSTREAM Consortium input into discussions during the project, especially Judy Orme and Laurence Carmichael, but also Jim Longhurst, Kris Ebi, Roderick Lawrence, Sophie Laggan, Ruth Larbey and Margarida Sardo. Thanks also to our external advisors-Neil Smith, George Ferguson, Yolanda Barnes, Ian Cox and Barra Mac Ruairí-for contributing their time at the start of the pilot to helping develop the initial thematic areas of enquiry. This paper has been benefitted too from broader consideration and input through the early development of the 5-year TRUUD research programme (Tackling Root Causes Upstream of Unhealthy Urban Development), which is funded through the UK Prevention Research Partnership and includes the British Heart Foundation, Cancer Research UK, Chief Scientist Office of the Scottish Government Health and Social Care Directorates, Engineering and Physical Sciences Research Council, Economic and Social Research Council, Health and Social Care Research and Development Division (Welsh Government), Medical Research
Council, National Institute for Health Research, Natural Environment Research Council, Public Health Agency (Northern Ireland), The Health Foundation and the Wellcome Trust. [76, 77]

Author Contribution All authors contributed substantially to this paper. Gabriel Scally conceived of and set out the starting methodology employed and had overall editorial control. Daniel Black sets out the main body of text, including the rationale for the pilot, and was responsible during the pilot, with Paul Pilkington, for oversighting of the method development, subsequent lessons learned and final editing. Ben Williams, Janet Ige and Emily Prestwood reviewed the paper following their central roles in method development and interview recording, coding and analysis. All figures in this paper were conceived and produced by Daniel Black.

Open Access This article is licensed under a Creative Commons Attribution 4.0 International License, which permits use, sharing, adaptation, distribution and reproduction in any medium or format, as long as you give appropriate credit to the original author(s) and the source, provide a link to the Creative Commons licence, and indicate if changes were made. The images or other third party material in this article are included in the article's Creative Commons licence, unless indicated otherwise in a credit line to the material. If material is not included in the article's Creative Commons licence and your intended use is not permitted by statutory regulation or exceeds the permitted use, you will need to obtain permission directly from the copyright holder. To view a copy of this licence, visit http://creativecommons.org/licenses/by/4.0/.

\section{References}

1. Littig B, Dexter LA, Ware A, Sánchez-Jankowski M. Elite and specialized interviewing. With a new introduction. Forum Qual Sozialforsch / Forum Qual Soc Res. 2006;2008

2. Wellcome. Our planet our health. London: Wellcome Trust.

3. Eaton E, Hunt A, Black D. Economic valuation of the health impacts of urban environment: Working Paper; 2020.

4. Black D, Pilkington P, Williams B, Ige J, Prestwood E, Scally G. Overcoming systemic barriers preventing healthy urban development in the UK: main findings from interviewing senior decision-makers during a three-year planetary health pilot, Springer Nature. London, UK; 2020.

5. Stern N. The Economics of Climate Change: The Stern Review. 2007 . https://doi.org/10.1017 /CBO9780511817434.

6. Barton H, Grant M, Mitcham C, Tsourou C. Healthy urban planning in European cities. Health Promot Int. 2009;24: i91-9. https://doi.org/10.1093/heapro/dap059.

7. HM Government. (2010). Healthy lives, healthy people: our strategy for public health in England. https://assets. $\mathrm{p} \mathrm{u} \mathrm{bl} \mathrm{i} \mathrm{s} \mathrm{h} \mathrm{i} \mathrm{n} \mathrm{g.} \mathrm{s} \mathrm{e} \mathrm{r} \mathrm{v} \mathrm{i} \mathrm{c} \mathrm{e.} \mathrm{g} \mathrm{o} \mathrm{v.}$ uk/government/uploads/system/uploads/attachment data/file/216096/dh 127424.pdf. Accessed Jul 5, 2019.

8. Dannenberg Frumkin H, Jackson RA. Making Healthy Places - Designing and building for health, well-being and sustainability. Washington, DC: Island Press; 2011. 
9. Barton H, Grant M. Guise R. Shaping Neighbourhoods. 2014. https://doi.org/10.4324/9780203986882.

10. Whitmee S, Haines A, Beyrer C, Boltz F, Capon AG, de Souza Dias BF, et al. Safeguarding human health in the Anthropocene epoch: report of the Rockefeller FoundationLancet Commission on planetary health. Lancet. 2015;386: 1973-2028. https://doi.org/10.1016/S0140-6736(15)60901-1.

11. Bentley I, Alcock A, Murrain P, McGlynn SSG. Responsive environments: a manual for designers: Architectural Press; 1985.

12. Willams K, Jenks M, Burton E. Achieving sustainable urban form. SPON. UK: Routledge Oxfordhsire; 2000.

13. Barton H, Grant M, Guise R. Shaping neighbourhoods: a guide for health, sustainability and vitality. Abingdon Oxfordshire, UK: Taylor \& Francis; 2003.

14. Urban Villages Forum. Urban villages: a concept for creating mixed-use urban developments on a sustainable scale. Sutton Coldfield, UK: Urban Villages Group; 1992.

15. Urban Task Force. Towards an urban renaissance: final report of the urban task force. London, UK; 1999.

16. Llewelyn DD. Urban design compendium: urban design principles. Design. 2007; https://doi.org/10.1080 /00994480.1973.10732231.

17. Yeang LD. Urban design compendium 2: Delivering quality places. London, UK; 2013.

18. Royal Town Planning Institute. Planning Horizons Promoting healthy cities: why planning is critical to a healthy future. London, UK; 2014.

19. Academy of Urbanism. Annual Congress X-health, happiness and wellbeing. Birmingham; 2015.

20. Urban Land Institute. Building healthy places initiative. Accessed July 52019.

21. Black D, Scally G, Orme J, Hunt A, Pilkington P, Lawrence $\mathrm{R}$, et al. Moving health upstream in urban development: reflections on the operationalization of a transdisciplinary case study. Glob Challenges. 2018;1700103 https://doi. org/10.1002/gch2.201700103.

22. Black D. Royal Society of Medicine conference - building health in to the urban environment: [Presentation] Looking upstream - the main barriers and opportunities to healthier urban development according to the UK's main delivery agencies. In. 2018 . https://www.rsm.ac. uk/events/epidemiology-and-public-health/2018-19/epm01 /.

23. HM Government. Industrial Strategy Booklet.; 2018. ht t ps:// a s sets.publishing.service.gov. uk/government/uploads/system/uploads/attachment data/file/364455/industrial-strategy-booklet-3.pdf. Accessed July 52019

24. Ige J, Pilkington P, Orme J, Williams B, Prestwood E, Black $\mathrm{D}$, et al. The relationship between buildings and health: a systematic review. J Public Health (Bangkok). 2018;41: e121-32. https://doi.org/10.1093/pubmed/fdy138.

25. Briggs DJ, de Hoogh K, Morris C, Gulliver J. Effects of travel mode on exposures to particulate air pollution. Environ Int. 2008;34:12-22. https://doi.org/10.1016/j. envint.2007.06.011.

26. Barton H, Thompson S, Burgess S, Grant M. In: Barton H, Thompson S, Burgess S, Grant M, editors. The Routledge Handbook of Planning for Health and Well-Being: Routledge; 2015.
27. Bird E, Ige J, Pilkington P, Pinto A, Pertokofsky C, BurgessAllen J. Built and natural environment planning principles for promoting health: an umbrella review. BMC Public Health. 2018;930

28. Frumkin H. Planetary health alliance annual conference 2017 - welcome \& meeting overview: what is planetary health and why now? Boston Massachusetts, USA; 2017.

29. Kickbusch I, Allen L, Franz CJ. The commercial determinants of health. Lancet Glob Health New York, USA. 2016;4(12):e895-6.

30. Williams K. Urban form and infrastructure: a morphological review.

31. Pain K, Van Hamme G. Changing urban and regional relations in a globalizing world: Europe as a global macroregion. Cheltenham, UK; Cheltenham: Edward Elgar; 2014.

32. Black D, Scally G, Hunt A, Orme J. We must look further upstream to enable planetary health-literate urban development. Lancet Planet Health. 2018;2(4):e145-6. https://doi. org/10.1016/s2542-5196(18)30045-7.

33. Pacione $\mathrm{M}$. The rhetoric and reality of public participation in planning. Urban Dev Issues. 2019;63(1):5-15. https://doi. org/10.2478/udi-2019-0012.

34. Innes JE, Booher DE. Reframing public participation: strategies for the 21st century. Plan Theory Pract. 2004;5:41936. https://doi.org/10.1080/1464935042000293170.

35. Tauxe CS. Marinalizing public participation in local planning- an ethnographic account. $J$ Am Plan Assoc. 1995;61:471-81. https://doi.org/10.1080 /01944369508975658.

36. Rydin Y, Pennington M. Public participation and local environmental planning: the collective action problem and the potential of social capital. Local Environ. 2000;5:153-69. https://doi.org/10.1080/13549830050009328.

37. Lane MB. Public participation in planning: an intellectual history. Aust Geogr. 2005;36:283-99. https://doi. org/10.1080/00049180500325694.

38. Hickey S, Kothari U. Participation. In: International Encyclopedia of Human Geography; 2009. https://doi. org/10.1016/B978-008044910-4.00113-9.

39. Durose C, Beebeejaun Y, Rees J, Richardson J, Richardson L. Towards co-production in research with communities. Connect Commun. 2012:1-15.

40. Allan K, Baldwin M, Wilkinson K, Woodall D. Co-production. In: Co-creating and co-producing research evidence; 2019. https://doi.org/10.4324/9781351263009-3.

41. Jasanoff S. States of knowledge: the co-production of science and the social order; 2004. https://doi.org/10.4324 19780203413845.

42. Nesti G. Co-production for innovation: the urban living lab experience*. Polic Soc. 2018;37:310-25. https://doi. org/10.1080/14494035.2017.1374692.

43. Campbell H, Vanderhoven D. Knowledge that matters: realising the potential of co-production. N8 Res Partnersh Econ Soc Res Counc ESRC. 2016:1-70.

44. Gibson A, Britten N, Lynch J. Theoretical directions for an emancipatory concept of patient and public involvement. Heal (United Kingdom). 2012;16(5):531-47. https://doi. org/10.1177/1363459312438563.

45. Vanleene D, Verschuere B, Voets J. Benefits and risks of coproduction. A preliminary literature review. IIAS Conf Coprod Publ Serv. 2015;20 
46. Oliver K, Kothari A, Mays N. The dark side of coproduction: do the costs outweigh the benefits for health research? Health Res Policy Syst. 2019;17(1):1-10. https://doi. org/10.1186/s12961-019-0432-3.

47. Blackburn J, Chambers R, Gaventa J. Mainstreaming participation in development. In: Making development work: development learning in a world of poverty and wealth; 2018. https://doi.org/10.4324/9781351324762-7.

48. Casadevall A, Fang FC. Specialized science. Infect Immun. 2014;82(4):1355-60. https://doi.org/10.1128/IAI.01542-13.

49. Malone T, Laubacher R, Johns T. The Big Idea: The age of hyperspecialization. Harvard Business Review. https://hbr. org/2011/07/the-big-idea-the-age-of-hyperspecialization. Published 2011. Accessed Apr 17, 2020.

50. ESRC Genomics Policy \& Research Forum, College of Humanities \& Social Science U of E. Bridging the gap between research, policy and practice: the importance of intermediaries (knowledge brokers) in producing research impact. In:. 2011. https://www.ktecop.ca/2011/bridging-thegap-between-research-policy-and-practice-the-importanceof-intermediaries-knowledge-brokers-in-producingresearch-impact/. Accessed July 52019

51. Robeson P, Dobbins M, DeCorby K. Life as a knowledge broker in public health. J Can Health Libr Assoc. 2008;29(3):79-82.

52. Kislov R, Wilson P, Boaden R. The 'dark side' of knowledge brokering. J Health Serv Res. 2017;22(2):107-12.

53. Leadership Foundation for Higher Education. Professional Managers in UK Higher Education: Preparing for Complex Futures.; 2008. https://www.advance-he.ac.uk/knowledgehub/professional-managers-uk-higher-education-preparingcomplex-futures-final-report. Accessed July 52019

54. Barton H, Grant M. A health map for the local human habitat. J R Soc Promot Heal. 2006;126:252-3.

55. EcoPlan. Health Impact Assessment of Transportation and Land Use Planning Activities GUIDEBOOK. 2015. https://ecoplan.ca/2017/10/18/post-7/.

56. BRE. BREEAM Communities: Technical Manual. 2012. https://www.breeam.com/discover/technicalstandards/communities/. Accessed July 52019

57. Healthy Urban Development Unit. HUDU Rapid HIA Tool. 2017. Accessed July 52019

58. Office of the Deputy Prime. The Egan review: skills for sustainable communities. 2004. Accessed July 52019

59. Aberbach JD, Rockman BA. Conducting and coding elite interviews. Polit Sci Polit. 2002;35(4):673-6.

60. Welch C, Marschan-Piekkari R, Penttinen H, Tahvanainen M. Corporate elites as informants in qualitative international business research. Int Bus Rev. 2002;11:611-28. https://doi. org/10.1016/S0969-5931(02)00039-2.

61. Mikecz R. Interviewing elites: addressing methodological issues. Qual Inq. 2012;18:482-93. https://doi.org/10.1177 /1077800412442818.
62. Smith KE. Problematising power relations in "elite" interviews. Geoforum. 2006;37:643-53. https://doi.org/10.1016 /j.geoforum.2005.11.002.

63. Liu X. Interviewing elites: methodological issues confronting a novice. Int J Qual Methods. 2018;17: 160940691877032 . https://doi.org/10.1177 /1609406918770323.

64. Littig B. Interviewing the elite-interviewing experts: is there a difference? New York, USA, Palgrave Macmillan; 2009.

65. Braun V, Clarke V. Using thematic analysis in psychology. Qual Res Psychol. 2006;3(2):77-101.

66. Silverman D. Doing qualitative research: a practical handbook. 4th ed;2013. https://doi.org/10.1017 /CBO9781107415324.004.

67. Black I. The presentation of interpretivist research. Qual Mark Res An Int J. 2006;9:319-24. https://doi.org/10.1108 /13522750610689069.

68. Berry JM. Validity and reliability issues in elite interviewing. Polit Sci Polit. 2002;35(4):679-82.

69. Lancaster K. Confidentiality, anonymity and power relations in elite interviewing: conducting qualitative policy research in a politicised domain. Int J Soc Res Methodol. 2017;20:93103. https://doi.org/10.1080/13645579.2015.1123555.

70. Blaikie NWH. A critique of the use of triangulation in social research. Qual Quant. 1991;25:115-36. https://doi. org/10.1007/BF00145701.

71. Thurmond VA. The point of triangulation. JNurs Scholarsh. 2001;33:253-8. https://doi.org/10.1111/j.15475069.2001.00253.x.

72. Robson C. Real world research, vol. 63: Blackwell Publ.; 2002. p. 1051-2. https://doi.org/10.1016/j. jclinepi.2010.08.001.

73. Carter N, Bryant-Lukosius D, DiCenso A, Blythe J, Neville AJ. The use of triangulation in qualitative research. Oncol Nurs Forum. 2014;41:545-7. https://doi.org/10.1188/14. ONF.545-547.

74. Berry JM. Validity and reliability issues in elite interviewing. In: PS - Political Science and Politics; 2002. https://doi.org/10.1017/S1049096502001166.

75. Riesman D. Orbits of Tolerance, Interviewers, and Elites. Public Opin Q. 1956;20:49. https://doi.org/10.1086/266597.

76. TRUUD Consortium. Tackling root causes upstream of unhealthy urban development. UKPRP. Accessed 27th April 2021. https://ukprp.org/what-we-fund/truud/.

77. UKPRP. UK Prevention Research Partnership. https://ukprp.org/. Published 2019. Accessed Dec 17, 2019.

Publisher's Note Springer Nature remains neutral with regard to jurisdictional claims in published maps and institutional affiliations. 